\title{
Electronic Marketing Management in Power Systems
}

\author{
Roozbeh Kargar ${ }^{1}$, Seyed M.H Nabavi ${ }^{2}$, Member, IEEE \\ ${ }^{1,2}$ Department of Electrical Engineering, Payame Noor University, PO BOX 19395-3697 Tehran,IRAN.
}

\begin{abstract}
In this paper, the importance of E-marketing, its relation with Ecommerce and its differences with classical marketing in power systems will be discussed. In addition, moving toward privatization, defining Marketing Budget, recognizing the target markets in power systems and the principles of electronic marketing including attracting the customers, developing interests, tendency toward buying the products are the other topics that will be discussed. Furthermore, in the following, the strategy of the web designing of the companies related to power systems based on the principles of electronic marketing including: building trust, helping customers, keeping the products and the websites up to date will be mentioned.
\end{abstract}

KEYWORDS: Electronic Marketing, Power Systems, Website design.

\section{INTRODUCTION}

Nowadays, the topics of Electronic commerce and Electronic business have become the practical goal in Information technology. What defines Electronic commerce is the relation between business to business and business to consumers. It is obvious that business relationships, particularly in industries like power, are not easily made. Introduction of the products, effective advertisement, strong public relations, recognizing the target market are among the many factors that reveals the importance of marketing. This importance will be highly recognized in time of trade in virtual world. It is clear that Marketing in the virtual world, as in this field the building of the company, the C.E.O ,the company representative ,sales department, advertisement management and the way of attracting customers trust will be in a few web pages.

At present, many research projects are underway to make virtual prototyping a standard tool for power systems [1-6]. For examples, Haug et al [2] had illustrated an integrated design environment for the virtual prototyping of vehicles while Zamora [5] had significantly improved the understanding and application of drilling. Xiang et al [7] had recently reviewed the research and development in the computational tools for power system design.

In this paper, the importance of e-commerce marketing in power systems will be discussed. In addition, the principles of emarketing including attracting the customers, developing interests, leaning in the direction of business the will be discussed. Besides, the web designing of the companies related to power systems based on the principles of electronic marketing including: building trust, helping customers, keeping the products and the websites up to date will be stated.

\section{THE IMPORTANCE OF ELECTRONIC MARKETING AND ITS DIFFERENCES WITH CLASSIC MARKETING}

Electronic marketing consists of a set of activities to meet the needs and desires of the human being through the internet. This definition is literally like the definition of classic marketing; however, the Electronic marketing occurs in the internet and they are different in their contents.

Marketing in the world of commerce is not a new topic and has been there since the first trades happened. In developed countries, this profession has been viewed as an important skill in trading for ages. What has made this topic so important in the global village is the breaking of the information boundaries and the search for customers around the world.

The generation companies and distribution companies of power systems used to look for customers in different cities and countries. Sometimes ended spending hours and days to persuade their customers and in the end they were not sure that the client for whom a lot of time was spent for the products to be introduced would or would not buy the products. However, know the managers of the companies sitting at their desks behind their computers can find customers for their products. Marketing in the virtual world has considerable advantages over marketing in the real world. Four of the main advantages are as follow [8]:

- $\quad$ Saving time

- $\quad$ Saving on the expenses

- $\quad$ vast target markets

- $\quad$ peace of mind

Therefore, using web based marketing makes the managers of the power systems far from daily problems and they can easily decide and gain better results.

\section{THE RELATION BETWEEN E- COMMERCE AND ELECTRONIC MARKETING}

In this paper, to clarify the relation between e-commerce and electronic marketing, an example is used as follows:

The manager of an electric company asked a web designer to design a website to sell the products or services. The designer has designed the website with all the necessary features such as the company's phone number, email address, fax, and address and put it on a web hosting service. Until now, the company has entered the world of Ecommerce, but should they expect to receive many phone calls or to have their email inbox full of product invoices or many customers waiting at the door. Surely, the answer will be negative. 
From this point, forward electronic marketing matters. It helps the power companies to detect the target markets and advertise their products in them and to know their partners and rivals better, to increase their sells and benefits, to improve their rank in search engines and take advantage of the internet to improve their site's traffic. In fact, E-commerce laid the foundation of e-business. Those companies who have stronger electronic marketing are more successful in this regard.

\section{A. Product and service selling of power systems on the internet}

Before entering the internet-trading world, there must be a product to be offered to the customers. Many of the power companies and spare parts manufacturers first start a web site and pay the membership and then they start thinking about the product and the advertising way. This is the point where they realize that instead of making money through the internet, they have only spent money and time on it [8]. The product type and whether it can be presented over the internet is the subject that needs prior notification while starting a site. It might be possible for the owners of the smaller companies to think that their products cannot sell as much as those of bigger companies. Consequently, they become reluctant of creating a website. It has to be kept in mind that in the virtual world, share of a retailer and a billiondollar company is only a web site. Therefore, the winner is the one who can have a better marketing.

\section{B. Moving toward privatization is the essential factor in electronic marketing in power systems}

One of the integral principals of entering the electronic marketing field is to motivate the private sector in order to enter the era of producing and selling its product. It is understood that as long as power system is run publicly in a country, competitive opportunities for marketing will be limited.

The following factors are to be considered in order for the private sector to enter and participate in an inclusive competitive market with the help of electronic marketing:

- Lay the appropriate foundation in order to enter the electronic commerce, setting the relevant regulations related ecommerce by authorities, establishing unions linked to IT industry in regional power suppliers, holding training course for the employees to learn e- business.

- Creating active up-dated web sites in regional power suppliers and generalizing them into the sub-contractors in order to hold internet purchases to find required products and spare parts.

- Foundation of a transparent market to present different products of various manufacturers and distributors of equipment and parts in this market.

- Crating especial incentives for those companies that have better products such as giving license or using ranking system approved by ministry power of Iran with regard to performance back ground, high quality, reasonable price, further programs, product innovation and etc, in a way that it allows customers to find the company ranking and make the comparison between manufacturers of different types of electric, telecommunication and electronic devices by visiting the companies web sites. Finally, they are able to make the best choice.

\section{Estimating budget for e-marketing in electrical system}

"Economical consideration" is a key factor to achieve to success in electrical companies. As a general principle in classic marketing, marketing budget is allocated once general budget is determined. There are various types of marketing budget such as annual budget or a percentage of selling or annual profit. In this regard, it is believed that the highest amount of budget should be spent during product introduction phase. It should be gradually reduced over the time when the product enter growth, maturity and decline stages in product life cycle (plc).on the contrary, in e-marketing, where the number of customers are unlimited and there is no other tools except advertising, reduction of marketing budget is not applicable. In e-marketing budget in the organization, business and advertising are tied. Therefore, it is required to find new customers for products or use new technologies to develop a product technology or introduce a new product in relevant market in case of satiation in the target market. It is worth mentioning that although a product may reach to decline and maturity stage in a market, it is probable that the same product has not reached to introduction stage in another market placed on different part of world. Therefore, in virtual marketing decline stage does not occur soon, which allows advertising for years without having a saturated market. Therefore, it could be said that in e-marketing, there is no similarity in field of budget reduction with that of classic marketing.

\section{Determination of target market for trade in virtual world of electrical system: moving toward}

Target market includes number of people that want or require a product or service. The question may arise at the beginning is how important recognizing of target market is and in which fields can it assist for the affiliated companies in the power system? One simple answer is that not all the internet users need the goods produced by these companies.. Their target must be to cover the majority of people who are in demand or need of the products over the internet and more importantly, with the concessions they offer, they can distract them from the competitors. It might be said that everyone can see the product presented on the internet and any person or company who wants it will order it. Therefore, determining the target market is meaningless! The following factors will clarify the answer:

- What is being presented over the internet is of crucial importance. Undoubtedly, the target market for different cables and lamps (which have a daily use), is much wider than that of transformer parts (which have limited customers and need more investigation for purchasing). It is possible that many companies and consumers are faced with these two subjects over the internet but the number of these customers will be widely different. Therefore, companies must introduce those products over the internet which has a wider market from the beginning and other products can be presented along with them.

- As a case in point, a certain product of a company has various applications in different countries and they introduce it over the internet, in what language? Many of the internet users might not be familiar with common internet language (English) or Farsi in Iran. Therefore, companies will lose many of their customers in the furthest parts of the world. It is worth mentioning that entrance of Brazilian language to the internet, there was a $40 \%$ increase in the number of internet users in this country and this meant a wider internet target market in this country and other countries [8]. In order to solve the language barrier in target markets, the important parts or the abstract of the commercial texts are to be translated into the language of the countries where the potential majority of customers have. The advertising method of a cable manufacturer and a consultant in the field of power system are different. It is not necessary for the wire manufacturer to use long texts while advertising. These companies must present the 
variety of wires and cables and their functions in different images. In contrast, a consultant company must more emphasize on the points about management and efficiency. As a result, there will be larger texts. Knowing the target markets will help the power companies to participate in the fields that are more important and attractive to their customers.

After describing the importance of target markets, the ways of recognizing them will be discussed.

- Doing a survey among friends, colleagues and acquaintances.

- Knowing the competitors tactics and search in order to find their target markets.

- Selecting a small group from current customers and gathering information in return for some concessions given to them

Overall, recognizing target markets will save the energy, cut down on the expenses, and leads the companies to have more profits.

\section{FUNDAMENTAL FORMULA OF ELECTRONIC MARKETING}

It seems vital to get the attraction of internet visitors to the subjects and articles pointed in equipment and parts sellers or related service providers. In electronic marketing, there is a basic formula to attract the visitors and change them into customers. This formula is known as AIDA. AIDA stands for Attention, Interest, Desire and Action.

In the section below the parts of AIDA is going to be discussed.

\section{A. Attracting the customers}

Researches show that companies have only 11 seconds to attract the visitors [2]. What draws the link visitors' attention is only and only the advertisement title? The advertisement title is the basic principal and the most important part of an advertisement. A title must be exiting and fascinating. Some of the slogans that are used in the titles are: (this is not an advertisement!), (lifetime after sell services), (buy two, get one free). What words to be used in a title is another point that company owners must consider. What words their products will be searched with is significant. Getting advice from web and power system professionals will be beneficial. The customers will not find the company unless a suitable tile is chosen. To accomplish the goal, company owners must assume than customers often have a few key words [10]. Thus, the words in the title must be found among the customers key words. The objective of attention section is to make the first impression not to think of the kind or the quality of the product. In fact in doing so, companies buy time to persuade the visitors to read the main article.

\section{B. Interest}

If a user clicks the company link over the internet or type the site address in the address bar the second step will start. In this step, attempts should be made to create motive for the company's product. The company managers should give a suitable answer to the question that how they are going to solve the costumers' problem. The details are unnecessary. If the company does its job well, the visitors might its address to their favorite list. In short, the interest section considers the service that the product can provide in order to improve the visitors life style.

\section{Desire}

When the interest has been made, they should be persuaded to buy. In this part, the highlighted features of the product must be considered. The text, which is written about the key features of the product, has to be attractive and interactive. This will create a good feeling in the visitors; however, the details must not be dealt in depth. This will bore them. Experience shows if the visitors do not like a sentence on the site they will not be willing to continue and they will simply leave the site. Therefore, the details should be avoided on the main pages. If the subject is so interesting that can keep up the readers with it, it could be hoped that they would turn in to costumers. To cut the long story short, the aim of the desire section is to deal with the key features of the products and what differentiates them from the rivals' products.

\section{Action}

If the previous steps are done properly and the company can keep the visitors, they will not be visitors anymore. They would be the costumers of the company. Click here to order, go to, call now clicking these buttons by the costumers is a real success for the seller. This means purchase. In this step all terms and conditions must be clearly explained and concessions should be considered as much as possible for the costumers. The down payment, the installments, buying on credit, bargain, and using prices like 99.95 can motivate the costumers. After sale services should not be ignored. For the costumers, warranty and support is more important the purchasing itself. In short, the aim of action section is to encourage the consumers to buy with the help of concessions, bargains and after sale services.

\section{STRATEGIES OF DESIGNING WEBSITE BASED ON MARKETING PRINCIPLES}

After working on the principles of electronic marketing, a question arises and that's: what tools are useful for selling more products and providing better services? In the following, methods for selling more, attracting customers' trust and how to keep in touch with them will be discussed.

\section{A. Building trust:}

One of the important factors in designing websites is to have the viewers and costumers' trust. Some points will help the companies in this regard.

- $\quad$ Promoting, discount and gift system for costumers

- Having warranty and after sale service for specially innovative products

- $\quad$ Using the word (YOU) in the website as the costumers are very sensitive to this word. A product just for You, what You asked for, special discount for You, our purpose is your satisfaction. This sentence provides the customers with a positive feeling and motivates them to continue searching the website [11].

- Designing the website with the help of expert website designers and power specialist

- Guaranteeing the security of financial transactions

- $\quad$ Avoiding using similar logos or names of other companies

- Having complete contact information. Making room for a part called Contacts Us or About Us and providing the name of the company, history of the company, Managers' name and the members of the board, email address, mailing address, and etc. 
- The more information costumers get, the more will be the sale of the product. Honesty is the best policy.

\section{B. Keeping the information, news and products up to date}

The products have to be in line with the latest technologies of the world. it is clear that having latest technologies used in the products helps better and more sales. In addition, there should be news and information related to the power system. Managers should try to be up to date so the costumers would visit their site on a daily basis.

\section{Costumer Relation System}

Helping and guiding the costumers to fulfill their needs without being confused $[12,13]$.this system should have these factors:

Designing the site in a hierarchical structure to have better access to different parts. Using other partner companies' link so the costumers can find whatever they need quickly [14]. Small companies can have famous companies link on their website in return to financial payments. This will cause famous companies to have more sales and the smaller companies have more creditability. Not only will this make better cooperation among companies but it also provides the site with heavier traffic and improves the sites rank.

\section{Keep in touch with costumers permanently}

There are considerable number of ways to keep in touch with costumers like email, newsletters, advertisement sites, books, papers, accepting other companies links [15]. A power company can benefit from a part called (your comments ) for costumers. Permanent costumers usually feel this part and sometimes will add pieces of news which even managers are unaware of them.

\section{CONCLUSION}

This paper presented some suggestions and hints to power system operators to help them prepare knowledge based web sites. In addition, the paper offered some critical and essential points to web site managers to motivate and attract customers to buy their products especially the electricity power.

Furthermore, the beneficial results of using electronic marketing management presented as follows:

- Knowing electronic marketing better, its relation with Ecommerce and its difference with classical marketing

- Providing a vast managerial view to move towards privatization, budgeting, and recognizing target marketing power systems.

- $\quad$ Suggesting expert solutions to be applied in electronic marketing in website designing for more traffic on the site and increasing sales and more importantly building trust and satisfaction for costumers.

\section{REFERENCES}

[1] Hamit F., New VR industrial simulation: virtual prototyping gets real, Advanced Imaging, 10(11), 1995.

[2] Haug E.J., Choi K. K., Kyung K., Kuhl J. G. and Wargo J., Virtual prototyping simulation for design of mechanical systems, Proceedings of the 1995 ASME International Mechanical Engineering Congress and Exposition, San Francisco, CA, USA, p 69-77.

[3] Martin J. M., Virtual engineering on the right track, Mechanical Engineering, 118(11), 1996, p 64-68.

[4] Dvorak P., Engineering puts virtual reality to work, Machine Design, 69(4), 1997, p 69-73.

[5] Zamora M., Virtual rheology and hydraulics improve use of oil and synthetic-based muds, Oil and Gas Journal, 95(9), 1997, p 43-55.

[6] Sa de, Gomes A., Zachmann G., Virtual reality as a tool for verification of assembly and maintenance processes, Computers and Graphics, 23(3), 1999, p 389-403.

[7] Xiang W., Fok S. C. \& Yap F. F., Computational Tools for Fluid Power system Design: Towards distributed artificial intelligence and virtual reality, Journal of Computer Applications in Technology, 13(6), 2000.

[8] Chloë Thomas, "Easy to avoid mistakes when starting an ecommerce business", 2012.

[9] D. Bishop, "Write for success", 2008.

[10] "Helping Businesses Improve Results Through TechnologyBased Marketing", www.improved-results.com

[11] J. S. Rhodes, "Usability before Promotion is a Recipe for Success.” 2006.

[12] Sean McVey, "Keep Your Website Navigation Simple.” Nov. 2012

[13] R. Beneteau, "Learn Internet Marketing”, 2009.

[14] Sh. M. B. Arrieta, "I have got my sit up but where are my hits?", 2007.

[15] J. Turner, "7 simple tips for making your web site more user friendly.", Feb 2007. 